I Fundação Getulio Vargas (FGV), Escola de Economia de São Paulo/

Fundação José Luiz Egydio Setúbal, São Paulo, SP, Brasil

marcos.silveira@fgv.br

https://orcid.org/0000-0002-0031-366X

II Universidade do Estado do Rio de Janeiro (Uerj), Instituto de Estudos

Sociais e Políticos, Rio de Janeiro, RJ, Brasil

rogerio.barbosa@iesp.uerj.br

https://orcid.org/o0oo-0002-6796-4547

Marcos Paulo Lucca-Silveira'

Rogério Jerônimo Barbosa "

\title{
O FUTURO DAS TRANSFERÊNCIAS DE RENDA NO BRASIL: DILEMAS EMPÍRICOS E NORMATIVOS PARA UM PROGRAMA PÓS-PANDEMIA E PÓS-AUXÍLIO EMERGENCIAL
}

Renda básica emergencial, auxílio emergencial, coronavoucher: nomes que se referem ao mesmo programa de transferência de renda do governo federal, elaborado em 2020, para aliviar os efeitos socioeconômicos da crise provocada pela pandemia da covid-I9. Desses termos, o segundo, auxílio emergencial, é o que consta oficialmente na lei I3.982/2020, que implementou a política. As variações terminológicas, contudo, não são fortuitas. Num gradiente, mapeiam interesses. De um lado, aqueles que enfatizam como tal programa poderia ser um primeiro passo para um programa social mais amplo, alguma modalidade de transferência de renda ampla e permanente. De outro, aqueles que enfatizam seu caráter eminentemente temporário, uma vigência estritamente vinculada à pandemia: um "vale" para os tempos de coronavírus.

Seja como for, o debate assim animado pelo contexto trouxe à tona (e para o centro da pauta política) a noção "renda básica" - seja para negá-la, seja para defendê-la. Vale dizer, o auxílio emergencial não foi um programa de renda básica, tal como o último é apresentado na literatura contemporânea. Em virtude do escopo mais abrangente e de valores transferidos mais elevados do auxílio emergencial, no entanto, projetos mais amplos de distribuição de renda passaram a despertar interesse. E, nesse meandro, tornaram-se ainda mais patentes alguns dos limites do principal programa em vigência no Brasil, o Programa Bolsa Família (PBF). Consequentemente, especialistas, movimentos sociais e políticos passaram a considerar a relevância de propostas mais ousadas. 
É verdade que diferentes versões e nomes para programas abrangentes de transferência de renda já vinham ganhando apoiadores nas arenas públicas de diversos países nos últimos anos (Gentilini et al., 20I9) - e também no Brasil. Nos últimos meses, porém, o debate se apressou e adensou. E, a despeito de toda literatura especializada preexistente, as experiências recentes adentraram por direções e caminhos novos, com avanços e aprendizados principalmente no campo das políticas públicas: preocupações com a viabilidade fiscal e política, a compatibilidade com programas sociais anteriores e a capacidade de implementação pelo Estado (por exemplo, Paiva et al., 202I). Nosso propósito aqui é o de realizar uma reflexão normativa centrada nessas contribuições recentes. Pretendemos lançar luz sobre os princípios subjacentes aos dissensos e disputas políticas sobre programas de transferência de renda e, partindo do caso brasileiro, realizar uma contribuição teórica de maior abrangência.

Em particular, apresentamos e discutimos o conceito de renda básica universal (RBU), recentemente bastante presente nos debates públicos. Embora nenhum dos projetos atualmente em pauta no Brasil proponha um desenho estritamente dessa natureza, a ideia vem inspirando projetos e tensionando as políticas existentes. Para os mais críticos, trata-se apenas de uma ficção, irrealizável, quase sempre transformada em um espantalho; para os defensores mais engajados, um ideal a ser perseguido e, mesmo, implementado. De toda sorte, é necessário compreendê-la. A literatura especializada no assunto é multidisciplinar, envolvendo os campos da filosofia, economia, ciência política, sociologia e outras áreas relacionadas. E essa multiplicidade de olhares multiplica também as controvérsias. Autores de espectros políticos radicalmente diferentes - como Thomas Paine (1797), Milton Friedman (I 968) e Martin Luther King Jr. (2010) - apresentaram propostas próprias que são vistas como precursoras ou relacionadas à noção de renda básica universal. ${ }^{\mathrm{I}} \mathrm{Na}$ discussão acadêmica contemporânea, a ideia está bastante associada aos trabalhos do filósofo político belga Philippe Van Parijs (I995; Van Parijs, Vanderborght, 20I7, entre outros). ${ }^{2}$ Apresentamos as caracterís ticas comuns das diferentes propostas normativas de renda básica e as razões morais, tal como elencadas por seus defensores, que fundamentariam sua adoção em um Estado justo. Assim poderemos iluminar algumas questões urgentes do cenário atual.

O artigo possui seis seções, contanto esta introdução. Na seguinte, apresentamos breve análise do contexto da pandemia e dos efeitos na distribuição de renda da adoção do auxílio emergencial no Brasil. Em seguida, identificamos os pontos tornados sensíveis na discussão pública atual, que se dirige aos limites do Bolsa Família e à eventual necessidade de reformá-lo. Abordamos então formalmente o conceito de RBU e seus componentes principais. Além disso introduzimos três perspectivas ou princípios de justiça norteadores de nossa análise normativa: o igualitarismo, o prioritarismo e o suficientismo. Mostramos como esses conceitos permitem fazer questões sobres os objetivos 
de políticas e sobre dilemas morais implicados nos desenhos e métodos de implementação. Na penúltima seção, articulamos as duas partes: o debate político atual, à luz dos princípios de justiça. Discutimos questões de financiamento e estabilidade temporal, e consideramos a elevada volatilidade de renda nos estratos mais baixos de renda. Argumentamos que os próprios princípios de justiça são modificados quando levamos em conta aspectos práticos e não ideais da realidade sobre as quais políticas são elaboradas. Por fim, tecemos algumas considerações.

\section{A PANDEMIA E O AUXÍLIO EMERGENCIAL}

Desde o início da pandemia, tornou-se claro que a crise econômica ali desencadeada agravaria a vulnerabilidade dos estratos mais pobres da população. Esses foram, em geral, ocupantes de postos de trabalho informais, que, pela ausência de vínculo contratual, puderam ser facilmente demitidos ou ter atividades paralisadas. Além disso, exerciam atividades pouco passíveis de realização a distância (via teletrabalho) - levando à manutenção do trabalho presencial e também à maior exposição à covid-I9 (Barbosa et al., 2020b). Barbosa, Prates e Meirelles (2020) mostram que, para cada trabalhador formal desligado, três informais perderam seus postos ou deixaram de trabalhar. Evidências apontam, porém, que o auxílio emergencial de fato foi eficaz em proteger economicamente as famílias mais pobres - a despeito de diversos problemas nas etapas iniciais de sua implementação (Barbosa et al., 2020a). Li et al., (202 I) evidenciam ainda que negros e pobres foram particularmente mais atingidos também pelas consequências sanitárias da crise, sofrendo mais hospitalização e mortes em decorrência da covid-ı9.

O propósito do auxílio emergencial foi o de tentar endereçar essas duas dimensões: compensar as perdas de renda dessas famílias e estimular a manutenção do distanciamento social (reduzindo a urgência da procura de empregos para aqueles que foram demitidos, por exemplo). Não se trata, portanto, de uma política desenhada para o combate a mecanismos regulares que geram pobreza e desigualdade - diferentemente do Bolsa Família. O programa inicialmente consistia no pagamento de cotas de $\mathrm{R} \$ 600$ a indivíduos que não trabalham ou que possuem trabalhos informais e vivem em domicílios de baixa renda (para detalhamento das regras, ver lei n. I3.982, de 2 de abril de 2020). Mães em famílias monoparentais (que cumprindo também os demais requisitos) tinham direito a duas cotas, isto é, R\$ I.200. Não poderia haver, contudo, o recebimento de mais de duas cotas por domicílio. ${ }^{3} \mathrm{~A}$ partir de setembro, os valores das parcelas subsequentes caíram pela metade: $\mathrm{R} \$ 300$ e $\mathrm{R} \$ 600$, res pectivamente. Em de 3I de dezembro de 2020, o programa foi descontinuado - no entanto, em abril de $202 \mathrm{I}$, foi retomado com novas regras, cobertura mais restrita e valores substantivamente inferiores.

No gráfico adiante, exibimos os valores dos rendimentos domiciliares per capita dos $40 \%$ mais pobres da população, comparando maio de 2020 (com 
e sem a incidência do auxílio emergencial) com a distribuição de renda observada em 20I9. Encontramos que, para a população localizada nos estratos entre os $2 \%$ e $35 \%$ mais pobres (percentis $\mathrm{P}_{2}$ ao P 35 ), a incidência do benefício fez com que as rendas dessas famílias chegassem a ser levemente superiores aos níveis de 2019 (resta saber se essa pequena parcela adicional seria capaz de gerar também o efeito epidemiológico desejado pelos políticos, a manutenção do distanciamento). A inexistência do auxílio implicaria perdas bastante intensas (linha tracejada).

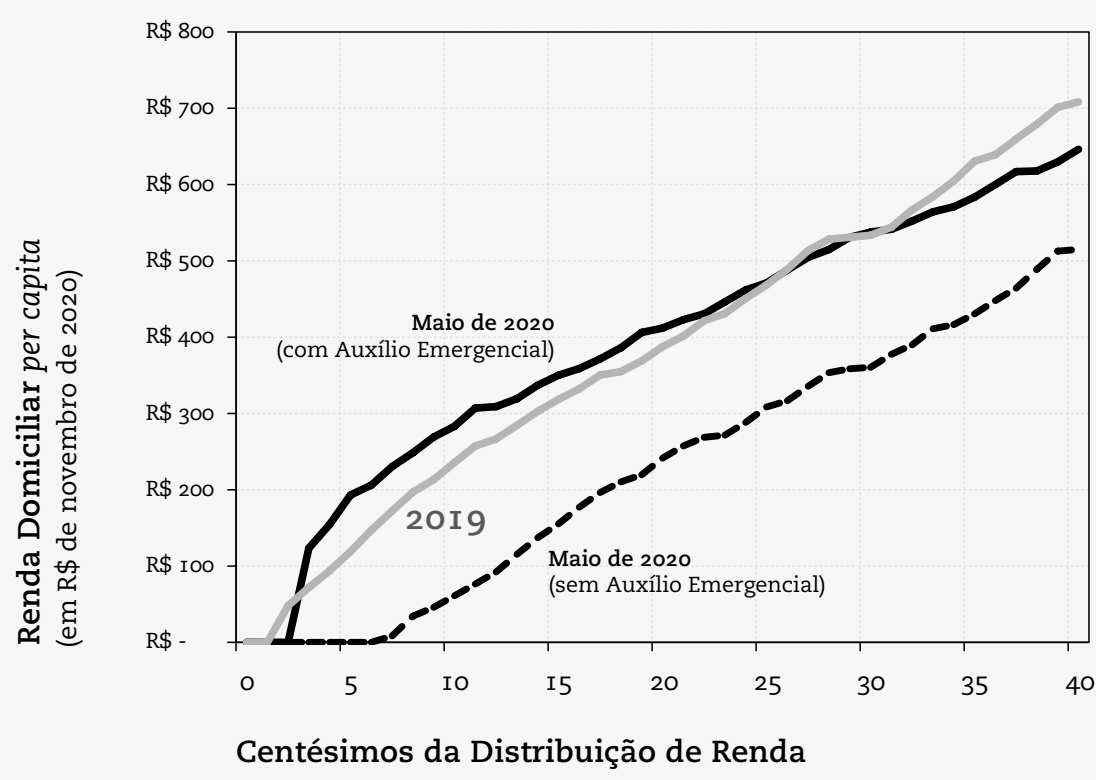

\section{Gráfico I}

Valor da renda domiciliar per capita, ordenada por percentis (Percentis PI a P40)

Brasil, 2019 e 2020 com e sem a contabilização do auxílio emergencial Fonte: Pnad Contínua Anual 20r9; Pnad-Covid, maio/2020. Elaboração própria. 
O gráfico seguinte, no entanto, com foco nos estratos intermediários (percentis $\mathrm{P}_{40}$ ao $\mathrm{P} 90$ ), mostra que esse mesmo efeito compensatório não se verifica para a classe média. Trata-se de uma população com renda um pouco mais elevada (a maior parte entre $R \$ 500$ e R\$ I.500 per capita) e com mais probabilidade de ocupar um posto de trabalho com carteira assinada - logo, em larga medida, inelegível ao programa emergencial.

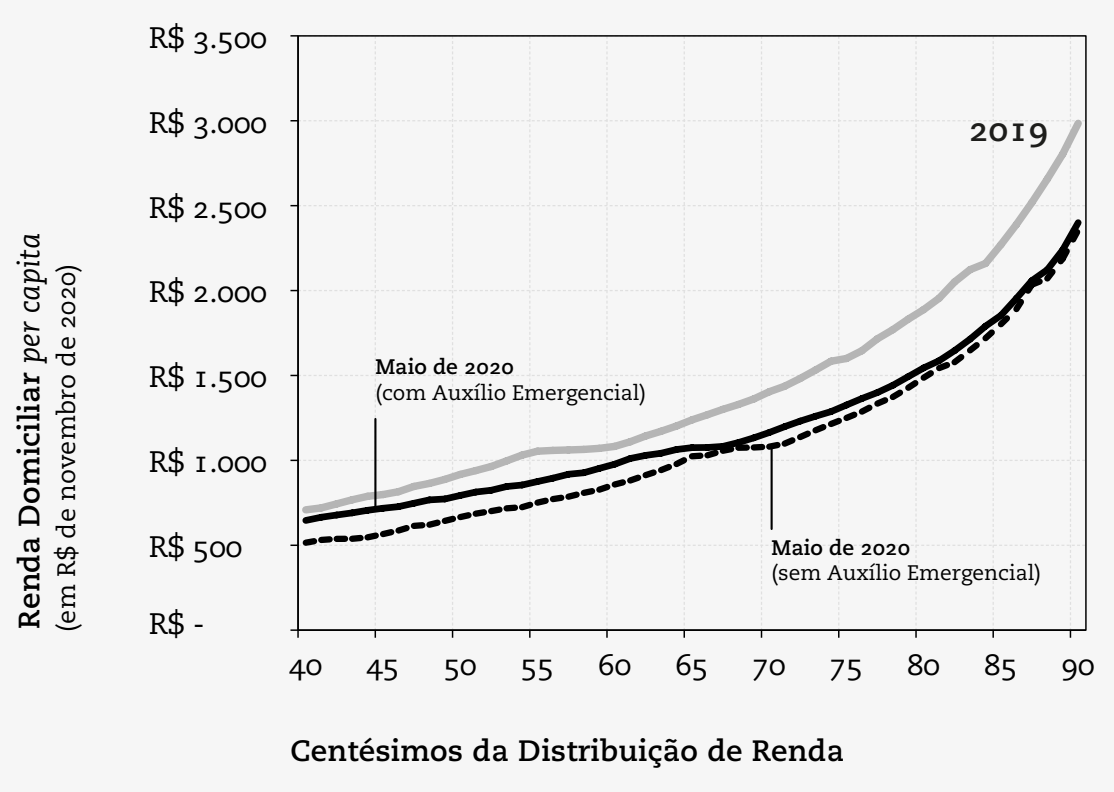

Gráfico 2

Valor da renda domiciliar per capita, ordenada por

percentis (Percentis $\mathrm{P} 40$ a $\mathrm{P} 90$ )

Brasil, 2019 e 2020 com e sem a contabilização

do auxílio emergencial

Fonte: Pnad Contínua Anual 20r9;

Pnad-Covid, maio/2020. Elaboração própria. 
Tal lacuna de proteção emergencial nesses estratos intermediários (em especial, até os $70 \%$ mais pobres) justifica, para alguns, a alcunha de "novos vulneráveis": um grupo que, sob circunstâncias comuns (incluídas crises econômicas "usuais"), não se veria sob risco de perda de emprego e renda (Barbosa, Prates \& Meirelles, 2020). Isso, obviamente, não iguala suas perdas efetivas e potenciais às verificadas nos estratos mais baixos.

Como a incidência do benefício concentrada entre os mais pobres de fato foi capaz de proteger essas camadas contra perdas de rendimento, houve queda da taxa de pobreza, de I8,7\% (em 20I9) para I4,9\% (na última semana de maio), ${ }^{4}$ conforme medida apenas em termos monetários. O coeficiente de Gini para a renda domiciliar per capita caiu de o,543 para o,487 no mesmo período embora esse resultado para desigualdade reflita também as perdas não compensadas no meio e no topo da distribuição (Hecksher \& Barbosa, 202 I). No entanto, com a redução do escopo de elegibilidade e dos valores transferidos, na versão do programa vigente a partir de abril de 202I, estima-se que esses efeitos redistributivos tenham sido quase completamente anulados (Nassif-Pires, Cardoso \& Oliveira, 202I).

\section{OS DEBATES DERIVADOS DO AUXÍLIO EMERGENCIAL}

É evidente que a contenção das perdas e efeitos socioeconômicos infringidos pela pandemia tem duração apenas durante a vigência da política - que, por definição, é emergencial; logo, temporária. Inicialmente desenhado para durar por apenas três meses, o auxílio emergencial recebeu prorrogações em função da própria extensão da pandemia. Sua prorrogação indefinida (como programa permanente), contudo, não seria fiscalmente viável: no início de sua vigência, mensalmente esse programa custava uma vez e meia o total de gastos anuais com o Bolsa Família.

O encerramento do auxílio, em dezembro de 2020, implicou súbita deterioração dos indicadores socioeconômicos - algo especialmente grave num ambiente de recuperação lenta dos mercados e da saúde fiscal do Estado. É nesse contexto que emerge no debate público a preocupação com a possibilidade de uma política permanente da mesma natureza: seria possível tornar também duradouros os efeitos positivos? Qual seria o desenho de tal política permanente subsequente e quais seriam os objetivos por ela perseguidos?

A novidade do auxílio emergencial deixou ainda mais evidente para os atores políticos que o valor da transferência de renda do Bolsa Família era, há bastante tempo, "insuficiente". As linhas de pobreza e extrema pobreza do programa (de $\mathrm{R} \$ \mathrm{I} 78$ e $\mathrm{R} \$ 89$, respectivamente) estariam abaixo dos custos alimentares e não alimentares "básicos" da população. ${ }^{5} \mathrm{E}$, além disso, o financiamento instável do programa fez com que, a partir de 20I4, em decorrência da política de ajuste fiscal, seu orçamento encolhesse, reduzindo o escopo de beneficiários e os valores médios por domicílio e per capita (Barbosa, Sousa \& Soares, 2020). 
O orçamento público brasileiro distingue entre gastos obrigatórios e discricionários. Os primeiros incluem toda a folha de pagamentos do Estado, a previdência e outros itens constitucionalmente estabelecidos (como Saúde e Educação). Os gastos com o Bolsa Família são classificados como discricionários, e, por isso, anualmente devem ser discutidos, negociados e definidos em meio às pautas orçamentárias. O programa então se adapta à verba disponível, reajustando ou não o valor dos benefícios e da linha de pobreza, aumentando ou diminuindo o número de beneficiários. E, como desde 2015 o orçamento foi comprimido pelo ajuste fiscal, houve sistemática redução do programa desde então.

Emergem daí duas percepções importantes: idealmente, no futuro, o Bolsa Família ou qualquer programa de transferência de renda permanente que sucedesse a ele ou ao auxílio emergencial não poderia padecer desses mesmos problemas. Seu benefício deveria ser mais elevado (o que significa levar em conta algum critério ou patamar de suficiência mais elevado) e seu financiamento estável, com pilares mais fixos; eventualmente constitucionais - o que significaria, de certa forma, compreender o programa como um direito. Assim argumentam, por exemplo, Paiva et al. (202I).

A susceptibilidade dos estratos médios aos efeitos socioeconômicos da pandemia despertou ainda uma preocupação com essa "nova" vulnerabilidade. A crise alongada e a lenta recuperação fazem com que a preocupação não recaia apenas sobre os mais pobres, mas também sobre esse grupo mais amplo de afetados. Estudos mais antigos já apontavam que grande parte da população experimenta intensa "volatilidade de renda" (Soares, 20Io). Trata-se da condição na qual, na ausência de renda com fluxo regular, domicílios experimentam variadas inseguranças. A volatilidade reduziria o bem-estar subjetivo dos indivíduos e os privaria da possibilidade de planejamento de longo prazo e da capacidade de investir em bens tanto materiais como imateriais (incluindo educação). Há evidências de que em algum momento ao longo de um período mais extenso de tempo, mesmo na ausência de recessão econômica, parcela razoável desse grupo terá experimentado a condição de pobreza (Soares, 2010), definida em termos operacionais como a incapacidade de aquisição de alimentos para satisfação de necessidades nutricionais, de acesso a serviços, transporte e moradia adequada (basic needs). Noutras palavras, ainda que uma fotografia em cross-section não necessariamente os capture abaixo de uma linha arbitrária de pobreza, é provável que, em algum momento, a tenham cruzado. Uma reivindicação a respeito dessa susceptibilidade ou "nova" vulnerabilidade possui urgência moral de uma perspectiva de justiça distributiva.

A focalização ampliada, que inclui essa classe média volátil, inaugura, porém, outro desafio. Usualmente, o critério de foco é alguma linha de renda domiciliar per capita: indivíduos abaixo do limiar são elegíveis. Para o Estado, que concede o benefício, no entanto, a renda domiciliar "observável" é apenas 
aquela formalmente declarada. Do ponto de vista das capacidades estatais, é virtualmente impossível ter controle contábil das rendas advindas de fontes informais - a não ser por meio da declaração verbal dos montantes recebidos (Souza et al., 2020). Com isso, emerge a preocupação de que indivíduos e famílias que se encontram apenas um pouco acima do limiar de elegibilidade do programa tenham incentivos para se "informalizar". Sendo a informalidade um problema histórico e crônico do mercado de trabalho brasileiro, passa a emergir no debate público o argumento de que a focalização não deveria se basear diretamente na renda. É a essa preocupação que responde, por exemplo, a ideia de uma "renda básica infantil" (Levy, Matsaganis \& Shuterland, 20I3; Soares et al., 2019) ou de benefícios híbridos, que combinassem transferências com base em critérios etários e de renda (como, por exemplo, os desenhos aventados por Paiva et al., 202 I).

Em função das taxas de fecundidade ainda mais elevadas entre os mais pobres (apesar de secularmente declinantes), a base da pirâmide etária é muito mais alargada entre essa população (Soares et al., 20I9). Como resultado, há uma desproporção de crianças e adolescentes vivendo em situação de pobreza. Uma renda dirigida a esse grupo, independentemente de suas condições socioeconômicas efetivas, acabaria, indiretamente, sendo focalizada nos mais pobres. Ou seja, uma "renda básica universal infantil" seria, na realidade, uma renda básica não universal com focalização indireta e sem teste de meios - isto é, diferentemente do Bolsa Família, por exemplo, que coleta informações, verificáveis ou não, que possibilitam a avaliação da vulnerabilidade ou a baixa renda para definição dos beneficiários (Mostafa \& Santos, 20I6: I4). Assim, o critério direto da renda é evitado, e as consequências adversas antevistas sobre o grau de formalização, contornadas.

Naturalmente, emergem outras questões: e as famílias pobres em que não há crianças? tal programa substituiria as demais políticas de transferência de renda existentes? Grupos divergem nas respostas. Ausência de crianças desperta para a necessidade de um princípio complementar de elegibilidade ou para a manutenção de programas de transferência com finalidades distintas em paralelo, como o próprio Bolsa Família - ou alguma versão de transferências focalizadas, em combinação, como aquela apresentada por Paiva et al. (202I). A renda básica deveria então apenas endereçar a volatilidade de renda, enquanto o BF manteria sua função de combate à miséria? Entrelaça-se aí a questão sobre as funções cumpridas também pelos programas de transferência: estariam elas absorvidas e contempladas por uma renda básica? Ou seria desejável abandonar alguns de seus objetivos de modo a garantir disponibilidade orçamentária para execução de um programa maior?

Por fim, o pagamento de uma quantia implicaria o descompromisso es tatal com respeito à provisão de serviços como saúde, educação e outras funções da assistência social? Não há, por ora, grandes defensores da substituição dos 
serviços por pagamentos no debate público brasileiro. Reconhece-se, no entanto, que se o valor do benefício pago for muito elevado, ele acabará por funcionar como um novo teto de gastos, na prática, comprimindo orçamentos de outras rubricas - e assim, inadvertidamente, reduzindo ou impedindo novos investimentos em áreas prioritárias. Manifesta-se, assim, uma preocupação combinada com o tamanho do programa, sua convivência com outros setores no leque de um estado de bem-estar.

\section{MAPA CONCEITUAL DA RENDA BÁSICA UNIVERSAL}

\section{Características fundamentais da RBU e princípios de justiça distributiva}

Nesta seção apresentamos uma grade analítica para analisar os pontos críticos destacados. Primeiramente definimos a noção de renda básica universal mais formalmente (para que, adiante, possa ser tomada como parâmetro de comparação). Em seguida apresentamos alguns princípios de justiça que serão fundamentais para nossa análise.

Segundo Bidadanure (2019), cinco características podem ser consideradas comuns às diferentes propostas de renda básica universal presentes na literatura. Em primeiro lugar, o benefício deve ser pago em dinheiro e não em forma de vouchers, produtos ou serviços. Em segundo lugar, os benefícios devem ser individuais. Isto é, diferentemente de quase todos os programas de transferência de renda, a RBU não deveria ter os domicílios ou famílias como alvo - logo, não poderiam ser baseados na renda domiciliar (ou familiar), nem ser destinados a um único membro da família. Em terceiro lugar, deve ser incondicional. O recebedor tem um direito inalienável a essa renda, não dependendo de qualquer contrapartida (por exemplo, frequência à escola, a programas de qualificação etc.) - seja ele rico ou pobre, jovem ou velho, trabalhador formal, informal ou desempregado. Em quarto lugar, o pagamento deve ser regular e periódico (por exemplo, pago mensalmente). Isso se contrapõe a propostas que sugerem o pagamento de uma única parcela ou montante em um dado momento da vida. ${ }^{6}$ Finalmente, em quinto lugar, não deveria haver critérios ou barreiras de elegibilidade; afinal, o benefício é universal. Critérios de classificação e distinção entre beneficiários e não beneficiários (por exemplo, pobres versus não pobres) tenderiam a criar estigmas e preconceitos sociais.

Segundo defensores, o adjetivo "básica" não deve ser visto como sinônimo de mínima (no sentido de mínimo de subsistência). A noção se referiria ao fato de que a renda derivada de outras fontes (entre elas, principalmente o trabalho) "suplementaria" as transferências regulares realizadas pelo programa (Bidadanure, 20I9: 486). Ela seria, assim, uma base à qual outras rendas se poderiam somar. Obviamente, definir tal quantia básica não é tarefa simples, mesmo em um cenário puramente teórico. Desse modo, a RBU, tal como apresentada na literatura contemporânea, seria um programa de transferência de renda com características bem próprias, definidas a partir de parâmetros ideais. 
Seus principais defensores se encontram principalmente no campo da filosofia política.

Partindo então desse ponto de vista, destacamos três princípios gerais de justiça distributiva, que balizam correntes filosóficas distintas e que poderiam ser mobilizados para compreender programas de transferência de renda, sejam eles focalizados (como o PBF) ou universais (RBU). Nos referimos aos princípios da igualdade, da prioridade e da suficiência (Lucca-Silveira, 20I7).

Os defensores do valor intrínseco da igualdade argumentam que a avaliação de uma transferência ou pagamento a ser realizado deve ser "sempre" feita de forma comparativa, levando em conta não apenas o indivíduo que se tornará recebedor do benefício, mas toda a distribuição. Trata-se assim de uma consideração relacional e abrangente, implícita na comparação, a qual avalia "sempre" toda redução de desigualdade como normativamente positiva. Assim, num caso-limite, a comparação levaria ao nivelamento do distribuendum em questão.

Segundo o princípio da prioridade, "beneficiar pessoas importa mais quanto em pior situação essas pessoas estiverem" (Parfit: 2002, IOI). Não é necessário levar em conta toda a distribuição: apenas uma comparação incompleta é realizada, posto que o argumento depende somente da identificação daqueles em pior situação econômica. Fora desse escopo, as demais distâncias e diferenças não são relevantes. O critério de decisão sobre um estado mais ou menos justo levaria em consideração apenas o que afetasse as pessoas mais mal posicionadas.

Já os defensores das doutrinas da suficiência ou teorias suficientaristas (Frankfurt, 20I5) não se importam com a igualdade (ou com outro ideal comparativo) nem defendem a prioridade irrestrita dos em pior situação. Segundo esse leque de teorias, o que importa moralmente é se todos têm o bastante para viver acima de um determinado limiar crítico, uma espécie de linha de suficiência. Indivíduos em pior situação relativa apenas serão relevantes se se encontrarem abaixo daquele patamar. Dessa forma, apoiadores dessas doutrinas defendem duas teses distintas, mas inter-relacionadas. Uma tese positiva - a afirmação da importância de que as pessoas vivam sem privações, acima do limiar de suficiência - e uma tese negativa - a negação da relevância de apelos distributivos adicionais (Casal, 2007: 298), uma vez que aquele limiar tivesse sido ultrapassado por todos.

Nosso argumento é o de que estes três princípios de justiça - igualdade, prioridade e suficiência - podem iluminar tanto considerações teóricas sobre renda básica universal como também parte do debate político sobre auxílio emergencial e renda básica realizado no Brasil. Fundamentalmente, um princípio de justiça pode ser compreendido como um critério último de justificação, capaz de fornecer bases de legitimação das reivindicações morais e demandas políticas por programas de transferência de renda em circunstâncias socioeconômicas específicas.

Intuitivamente, o princípio da igualdade poderia ser considerado o mais "forte" ou exigente. Ele tende a justificar políticas redistributivas mais demandantes que as defendidas pelos princípios da prioridade e da suficiência. Cete- 
ris paribus, um igualitário considera um cenário com desigualdades - por exemplo, de renda, ou, nos termos da literatura especializada, de bem-estar -, sempre inferior a um cenário sem (ou com menos) desigualdades. No limite, o cenário preferido seria aquele de completo nivelamento do equalizandum.

Segundo a visão prioritarista, deveríamos promover políticas públicas que satisfizessem as preferências com menor nível de renda ou bem-estar. Prioridade, desse modo, definiria os primeiros indivíduos a ser beneficiados por ações distributivas. Há, contudo, diferenças com respeito à noção de "focalização" de uma política pública. A prioridade, definida de forma monista (isto é, sem associação ou com outros princípios), seria irrestrita: enquanto houver distribuendum, podemos realizar atos distributivos, desde que satisfeito aquele critério. Numa sociedade afluente, por exemplo, o primeiro (ou próximo) indivíduo a ser beneficiado por uma política prioritária pode não ser considerado "pobre", segundo alguma linha de pobreza. Não se trata de uma avaliação de insuficiências ou necessidades, mas de um critério meramente ordinal. Por essa razão, por ser irrestrito, consideramos que o prioritarismo é mais exigente do que o princípio da suficiência.

Os defensores da doutrina da suficiência entendem que as demandas daqueles em pior situação apenas devem ser consideradas se estiverem também abaixo do limiar de suficiência. Em outras palavras, em uma sociedade em que todos vivem acima de alguma linha de pobreza absoluta, adeptos da doutrina da suficiência podem considerar que não há razões para realizar políticas públicas em prol dos "menos ricos" que os demais. Desigualdades remanescentes (e noções correlatas, como a de pobreza ou privação relativa) não seriam objeto de interesse. Nesse sentido, o princípio da suficiência é o menos exigente dos três. ${ }^{7}$

Essas três perspectivas propiciam a formulação de diferentes objeções à desigualdade econômica e à pobreza e autorizam diferentes justificações morais para programas de transferência de renda. À primeira vista, as características da RBU, apresentadas acima, podem soar como inspiradas e justificadas pelo princípio da igualdade, que seria avesso à existência de toda forma de desigualdade econômica.

De um ponto de vista moral, a justificação moral de um programa de transferência de renda específico decorre de considerações sobre as circunstâncias preexistentes, prováveis consequências e cenários decorrentes de sua implementação. Ou seja, o ponto de partida importa, e uma antevisão de seus efeitos também. John Roemer (2004) argumenta que uma visão ética, para ser atrativa, precisa ser contextual, eclética e pluralista - em suma, sensível às circunstâncias e aos cenários vigentes. Acreditamos que o argumento é válido para políticas públicas: diferentes razões morais, algumas mais demandantes (e provavelmente com um menor número de adeptos) e outras menos exigentes podem legitimá-las. 
É verdade que demandas democráticas e políticas públicas não precisam ser justificadas ou identificadas a uma abordagem teórico-normativa específica. Usualmente, para fins práticos e de governança, estudos empíricos de avaliação da implementação e do efeito de políticas são muito mais demandados. Isso não significa, contudo, que não devamos refletir sobre os valores que balizam nossas decisões políticas. Refletir sobre o princípio moral orientador traz clareza a respeito da sociedade em que desejamos viver.

E reside aí a relevância de se identificar como aqueles três princípios normativos poderiam formatar nosso entendimento sobre um programa de renda básica universal. Se não debatermos nossas motivações morais primeiras, sempre estaremos correndo o risco de sequer distinguir entre aliados e opositores políticos. Apenas quando sabemos aonde queremos chegar é que se torna possível escolher o melhor caminho a seguir. É verdade que consequências importam. Justamente por isso, faz sentido perguntar que consequências buscamos.

\section{DAS FINALIDADES E CONSEQUÊNCIAS DA RENDA BÁSICA UNIVERSAL}

A RBU é uma proposta originalmente com matiz libertariana. De acordo com Van Parijs (I994: 7I), se queremos ser justos, devemos almejar uma sociedade livre, na qual seus membros possuem tanta liberdade quanto possível. O ins trumento adequado para isso, advoga o filósofo belga, seria uma renda básica universal. Talvez alguns leitores se espantem, tendo em vista o fato de que, no imaginário, essa seria uma ideia frequentemente associada à presença forte de um Estado de esquerda. De acordo com o próprio Van Parijs (I995), sua proposta é de um "libertarianismo real", o que não é contraditório com um núcleo igualitário da proposta ou pode vir a ser adotada por igualitários. Ainda que estejamos tratando de rendimentos, o equalisandum de fundo não é o mesmo: em vez da ênfase em resultados distributivos, uma ênfase na equalização das oportunidades ou condições, ampliando liberdades. A RBU poderia reduzir opressões econômicas, de gênero e raciais. Essas são razões morais abrangentes listadas na literatura, ${ }^{8}$ conectando liberdade e igualdade. Se todos, independentemente de suas escolhas e trabalhos, possuírem uma renda básica, as principais formas de dominação e opressão existentes, argumentam, seriam reduzidas de forma significativa. Hierarquias que privam indivíduos de exercer suas liberdades de escolha e de ação possibilitando que vivam tal como desejam seriam mitigadas ou eliminadas. Justamente por isso, razões libertarianas são complementadas por outras razões morais, tanto liberais como igualitárias, na justificação da RBU.

Outro aspecto fundamental da justificação moral dirige-se à relação com a esfera do trabalho. Ao se constituir como um recebimento livre de contrapartidas, a RBU se choca com noções que hierarquizam posições no mercado - e ainda, de modo mais geral, priorizam o trabalho acima do tempo livre ou do lazer. Nesse ponto, há mais polêmica. Defensores enfatizam que não haveria 
razões para pressupor um valor moral superior (usualmente associado a ideias de reciprocidade social) de determinadas ocupações ou atividades. Indo além, seria válido questionar: todos devem ter o direito de fazer o que quiserem, incluindo não trabalhar, e mesmo assim receber uma renda básica de igual valor? Para usarmos o exemplo clássico da literatura: até mesmo um surfista em Malibu?'9 Segundo os defensores da RBU, sim. Trata-se do questionamento explícito do "produtivismo", que enaltece o trabalho e as responsabilidades individuais. Valores dessa natureza são podem ser compartilhados de modo tão tácito a ponto de impedir que outros princípios (como os da igualdade, prioridade e suficiência) sejam discutidos. Haveria um limiar de suficiência do trabalho? Haveria algum grau de produtividade social que pudesse efetivamente "libertar" indivíduos da necessidade de se engajar em atividades laborais? A necessidade do trabalho se justifica moralmente por quais razões não econômicas?

Deveria a RBU ser entendida como um "valor em si mesmo", independente das consequências e externalidades que poderia acarretar? Esse não é um ponto consensual na literatura contemporânea. Por um lado, não parece plausível que a "liberdade real" anunciada pelos advogados da RBU seja facilmente alcançada mesmo sob a hipotética vigência do programa. Por outro, a existência de tal programa pode conflitar com outros objetivos e valores sociais. Em que medida estaríamos desestimulando aqueles que executam funções mais difíceis? ${ }^{10}$ Estaríamos incentivando menores taxas de participação, logo uma economia menos dinâmica e menor bem-estar agregado? E em que medida esse seria apenas um mero receio daqueles já imensos numa cultura produtivista?

Pensar em aspectos práticos relacionados à implementação e vigência em situações reais ajuda a pensar de forma ainda mais ampla no escopo desses dilemas. Uma RBU seria fiscalmente viável? Isso é particularmente importante em países mais pobres ou em crise. Outras políticas realizadas pelo Estado poderiam perder financiamento em função da RBU? A RBU seria defensável se gerasse inflação?

Na próxima seção, partindo de uma reflexão sobre a experiência do auxílio emergencial e dos debates por ele suscitados, apresentamos algumas considerações normativas sobre os temas centrais dos debates políticos acerca do futuro dos programas de transferência de renda no Brasil.

\section{DILEMAS NORMATIVOS EMERGENTES NO DEBATE BRASILEIRO"1}

Em uma sociedade tão desigual e com níveis tão elevados de pobreza como a brasileira, parece claro que qualquer uma das três perspectivas de justiça igualitarismo, prioritarismo e suficientarismo - seria compatível com algum tipo de política de transferência de renda. Mas todas elas defenderiam necessariamente a RBU? Essa questão não tem uma resposta fácil. Em princípio, políticas focalizadas poderiam ser preferidas pelas três posições. Uma distri- 
buição converge mais rapidamente para a igualdade quando transferências são realizadas entre partes extremas da distribuição: do topo para a base (Sen \& Foster, I997). Em contextos empíricos, isso ocorre, por exemplo, quando políticas de taxação progressiva no topo são combinadas com transferências focalizadas na base. Essa seria uma razão para igualitaristas defenderem tais medidas. É possível também argumentar que, para os prioritaristas, ainda que focalização não seja o mesmo que conferir prioridade àqueles em pior posição, seria razoável que, em contextos reais, essa seja uma possibilidade de implementação. E para os suficientaristas, por fim, transferências concentradas justamente no grupo que está abaixo do limiar de suficiência estão na primeira ordem de importância. Desse modo, sob quais condições a RBU seria defensável, em contraposição à focalização?

Primeiramente cabe pensar sobre os limites dos programas com estratégias de extrema focalização, como o próprio Bolsa Família. Não é difícil observar que, em contextos empíricos, a focalização jamais é perfeita. Ela usualmente é baseada no atendimento a algum critério explícito: ser pobre, estar desempregado etc. Do ponto de vista do Estado, isso depende da averiguação formal da condição de vida; o que a literatura denomina teste de meios - e são os mais pobres e mais mal posicionados justamente aqueles que com maior probabilidade podem não possuir meios de comprovação. São várias as razões: distância ou inacessibilidade dos serviços públicos, falta de informações e conhecimentos sobre o funcionamento de programas, falta de documentos etc. Um caso extremo seria, por exemplo, o das populações em situação de rua, que sequer podem comprovar endereço e composição familiar. A concessão de uma renda incondicional e universal poderia ser uma estratégia para contornar essa dificuldade - sendo, nesse sentido, consonante com prioritarismo (ao levar em conta essa característica fundamental dos mais mal posicionados) e talvez também suficientarista (alavancando os mais distantes para próximo ou acima do limiar de suficiência).

A experiência da implementação do auxílio emergencial durante a pandemia deixou evidente o quão difícil é identificar e chegar até os indivíduos que são foco de um programa: ausência dos elegíveis nos cadastros oficiais do governo, erros graves de focalização e concessão de benefícios etc. E, como argumentamos, a trajetória recente do Bolsa Família, antes da pandemia, evidencia que a abrangência do programa esteve à mercê de disponibilidades orçamentárias e disputas políticas. Noutras palavras, a operacionalização empírica dos critérios de foco e elegibilidade não mantém necessariamente uma correlação direta com as necessidades da população - e nem mesmo com linhas justas de suficiência.

A destacada distância entre os valores médios dos benefícios do Bolsa Família e o custo de vida da população é outra evidência adicional daquela ausência de correlação. Foco, desse modo, não é necessariamente sinônimo de 
eliminação efetiva da pobreza. ${ }^{12}$ E vale mencionar que o Programa Bolsa Família possui uma linha própria de pobreza, cuja atualização e deflação está também sujeita à disponibilidade orçamentária. Quando há desatualização, pode haver automática redução do número de pobres, conforme computados pelo programa, mesmo que os indivíduos beneficiários não tenham experimentado qualquer melhoria de vida.

A instabilidade do financiamento do Bolsa Família é apenas consequência do fato de que os benefícios transferidos não são entendidos como um "direito" - diferentemente do que ocorre, por exemplo, com as transferências do benefício de prestação continuada (BPC) e previdenciárias; ambos constitucionalizados. A estratégia de constitucionalizar políticas é uma tentativa de torná-las mais fixas e resistentes à mudança (retrenchment). ${ }^{13} \mathrm{~A}$ constitucionalização, contudo, não é sinônimo de entender uma política como direito, isto é, atrelada à própria noção de cidadania (tal como as liberdades civis e políticas). O Bolsa Família, apesar de duradouro, é ainda entendido como "emergencial", de vários modos (ainda que não nos termos do auxílio emergencial). É emergencial do ponto de vista dos indivíduos e famílias: acudindo pessoas em situações de extrema privação, estados de verdadeira emergência e urgência. Isso não impediria, em princípio, que fosse compreendido como direito - nesse caso, o direito de não viver sob extrema privação.

De certo modo, o seguro-desemprego é também uma política emergencial, em sentido análogo: volta-se para amenizar situações extremas no curso de vida. É frequentemente compreendido como um direito do trabalhador formal. A diferença, no entanto, reside no lastro que possui com o trabalho realizado anteriormente pelo indivíduo e pelas contribuições por ele recolhidas durante esse período. Assim o recebimento do seguro-desemprego baseia-se numa contrapartida contributiva prévia - o que o liga a ideias sobre retribuição e merecimento, por exemplo. É um direito conquistado em função de uma ação e não algo derivado da própria condição de cidadania.

O caráter não contributivo das transferências assistenciais suscita, nos críticos, o receio de que elas poderiam criar uma classe de dependentes do Estado. Em larga medida, a existência de condicionalidades comportamentais (como a exigência da frequência à escola ou serviços de saúde) opera como uma maneira de exigir contrapartidas sociais alternativas, a despeito do caráter não contributivo. Nesse sentido, condicionalidades auxiliam a justificar moralmente a existência de um programa para aqueles que temem o advento de uma grande coalizão de caroneiros (free riders), ferindo princípios de mérito e recompensa. Vale relembrar, porém, que uma das cinco características de um programa de renda básica é justamente estar associada à noção de direito inalienável, por ser incondicional. Nesse sentido, o BPF não é "básico".

O Bolsa Família pode ser visto como "emergencial" também de um ponto de vista macroeconômico e microfundamentado: idealmente, podemos supor 
que o crescimento econômico (conjugado a avanços distributivos e políticos) poderia eliminar por completo a existência da pobreza; logo a necessidade de um programa focalizado/emergencial - assim como o auxílio emergencial deixaria de ser necessário na ausência da pandemia e suas consequências. Tudo se passa, todavia, como se esperássemos o Godot do crescimento inclusivo. E o emergencial se torna cotidiano, sem se converter em permanente.

As necessidades da população podem ainda variar de forma dinâmica, em função da volatilidade e instabilidade das condições de vida e de renda. Isso significa que a posição relativa e absoluta dos indivíduos na distribuição de renda e bem-estar varia ao longo do tempo - o que dificulta tanto a identificação precisa daqueles em pior situação (critério prioritarista) como a avaliação da suficiência dos meios de vida (critério suficientarista). Do ponto de vista de um programa focalizado, isso pode ter várias implicações. A primeira delas é que o teste de meios deve ser também dinâmico - o que pode aumentar drasticamente os custos administrativos e informacionais do Estado. Na prática, é impossível manter o acompanhamento em "tempo real" das flutuações e necessidades da população, o que leva à implementação de alternativas aproximadas. No caso do Bolsa Família, houve, em 2012, a instituição do benefício de superação da extrema pobreza (BSP) um pagamento adicional destinado às famílias que, mesmo recebendo o benefício básico do programa, ainda não logravam ultrapassar a linha administrativa de pobreza. O diferencial pago era exatamente o hiato: a distância entre a renda comprovada à assistência social e o critério de pobreza do programa. No entanto, como o cadastro das famílias apenas é atualizado a cada dois ou três anos, o valor do BSP deixa de ter correlação com as variações de curto prazo das necessidades das famílias. $\mathrm{Na}$ prática, do ponto de vista dos beneficiários, trata-se apenas de um benefício fixo adicional. E vale observar que os mesmos tipos de desafios estariam dados para um programa de transferência (ou renda básica) do tipo "imposto de renda negativo", tal como na formulação célebre de Milton Friedman. Se as quantias a receber são determinadas com base no hiato com respeito a uma linha de insuficiência, então estamos assumindo que os mesmos requisitos informacionais exigentes devem ser satisfeitos.

Em nosso entender, a preocupação com a volatilidade de renda pode ser compreendida como uma reivindicação de justiça, que merece por si só atenção especial de uma perspectiva normativa. Ao se a levar em consideração, os três princípios passam a requerer consideração em perspectiva diacrônica. Trata-se da preocupação com a garantia de que ninguém enfrente privações em nenhum estágio de sua vida. Oscilações, instabilidades e privações intermitentes prejudicam as capacidades de fazer planos de vida, investimentos pessoais - o que afeta diretamente o bem-estar material e subjetivo, bem como o senso de liberdade e de possibilidade de assumir riscos. Os desafios para os princípios de justiça, no entanto, são diversos. Para o prioritarismo: como ordenar indivídu- 
os, do mais mal ao mais bem posicionado em alguma dimensão normativamente relevante, quando há trocas dinâmicas de posição? Para o suficientarismo: como estabelecer uma linha de suficiência que leve em conta essas variações? Bastaria simplesmente elevar seu patamar para além do limiar típico de variação? Para o igualitarismo (radical): como garantir que, mesmo se as rendas fossem completamente equalizadas, elas permaneceriam em equilíbrio/steady state? De início, poderíamos pensar que o prioritarismo se satisfaria com posições relativas "médias" dos indivíduos ao longo do tempo. Para o suficientarismo, a renda média ou o consumo médio poderiam talvez ser avaliados contra uma linha de suficiência fixa. Para o igualitarismo, bastaria observar a distribuição também média. Esbarramos, no entanto, no fato de que qualquer observador não possuiria informação completa e instantânea - para então as registrar e calcular médias. Observar uma vez a cada dois anos (como faz o Cadastro Único no Brasil) pode ocultar variações de curto prazo - mesmo se assumíssemos que todos os comprovantes e testes de meios trouxessem informação completa. Qual seria a periodicidade adequada? Deveríamos assumir que a volatilidade tem temporalidades idênticas para todos os indivíduos? Além disso, para que posições e médias passadas funcionem como critérios razoáveis para calibrar benefícios é necessário supor que eventos futuros se comportarão de modo razoavelmente semelhante - o que pode não ser o caso. No limite, ainda que houvesse regularidade, o formato das tendências poderia simplesmente não ser linear ou estável em torno de um ponto fixo; de modo que uma simples média poderia não ser uma estimativa adequada.

No debate contemporâneo entre especialistas e gestores de políticas públicas no Brasil, levantou-se a ideia de que benefícios maiores e para uma população muito mais abrangente do que a coberta pelo Bolsa Família poderia ser uma alternativa pragmática e viável (Paiva et al., 202 I). Parcela não desprezível da população que experimenta volatilidade de renda (em diferentes graus) pode ter vivenciado situação de pobreza em algum ponto do curso de vida. A rigor, pensar diacronicamente significaria estabelecer esse contingente como público-alvo de um programa - mesmo que, num dado momento específico, não houvesse indivíduos abaixo de uma linha de pobreza ou nenhum deles figurasse entre os mais mal posicionados. Seria essa uma medida contra toda a instabilidade provocada pela volatilidade de renda? Uma linha de suficiência elevada ou um critério alargado e diacrônico de prioridade seria um meio de garantir segura e preventivamente que não haveria insuficiência no futuro e que os mais necessitados (nesse sentido amplo) estão sendo cobertos, ainda que não seja possível identificá-los individualmente com precisão?

Supondo que haja um continuum de possibilidades entre programas extremamente focalizados e uma verdadeira renda básica universal, nossa argumentação parece apontar na direção de algo no meio do caminho, coerente com diversas perspectivas sobre justiça e dando especial atenção aos aspectos não 
ideais suscitados por sua implementação. E cabe sempre destacar: apesar de desenhada para ser realizada como uma política pública específica, uma real experiência de RBU é ainda inexistente no mundo. Modelos e implementações particulares apenas se aproximam em graus daquelas cinco características que a definem. Países, províncias e municípios que adotam algum tipo de transferência de renda abrangente sempre encontram à sua frente o dilema de qual característica abandonar, não satisfazer ou flexibilizar.

Um programa amplo que respondesse às dificuldades elencadas acima estaria mais próximo da flexibilização dos critérios de elegibilidade, das condicionalidades e dos testes de meios, mesmo que não fosse ainda concebido como direito inalienável de todos - e como vimos a noção de "direito" esbarra ainda na própria estratégia de financiamento do programa, que deveria, nesse caso, ser perene, estável e protegida contra flutuações e tentativas de ajuste fiscal. Ou então, a volatilidade do Estado se propaga e se converte em volatilidade dos direitos.

Outras questões, contudo, precisam também ser mais bem endereçadas. A literatura sobre renda básica assume que a universalização eliminaria os estigmas causados por programas com focalização. A direção da seta causal, porém, não é clara: seria a focalização a causadora de estigma ou seriam as populações já previamente estigmatizadas aquelas que se tornam alvo de políticas com ares de segregação? Se este último for o caso, a universalização pouco colaboraria. É possível mesmo que haja "causalidade recíproca” ou endogeneidade. Sob restrições orçamentárias e existência de desigualdades e insuficiências prévias, a universalização impõe ainda um "trade-off moral": seria "justo" desenhar um programa universal uma vez que há hierarquias e heterogeneidades nas necessidades de diferentes camadas sociais e recursos escassos/finitos para transferir?

O debate existente no Brasil sobre as diferentes estratégias de focalização, direta e indireta, lança luz sobre outro de relevância moral, de cunho consequencialista: devemos defender uma renda básica independentemente de seus efeitos e externalidades? A informalidade como possível externalidade negativa de um sistema de focalização direta (com testes de meios) e abrangente (com elevada linha de suficiência ou de pobreza) sugere a relevância de levar as consequências em consideração antes de nos manifestar como favoráveis ou contrários a um programa de transferência de renda mais amplo.

Diferentes princípios de justiça podem justificar programas distintos de distribuição de renda. Se é verdade que todo igualitário, prioritário ou suficientarista reconhece que não devemos viver em uma sociedade em que pessoas vivem abaixo do limiar de pobreza extrema, isso não significa que as políticas a ser defendidas por diferentes princípios de justiça serão semelhantes. Trata-se menos de escolher um princípio único como parâmetro para uma política real do que de derivar de cada um questões e avaliações sobre os objetivos que 
almejamos, os métodos para alcançá-los e as consequências (morais e práticas) de sua consecução. Noutras palavras, não é caso de "optar" entre igualitarismo, prioritarismo ou suficientarismo, tal como aqui definimos. Achamos mais frutífero uma abordagem pluralista, que permita a combinação desses princípios. Justamente por isso uma reflexão normativa pode auxiliar as avaliações e as recomendações empíricas, assim como esclarecer o debate político. $\mathrm{O}$ inverso também é verdadeiro: a teoria normativa precisa considerar as evidências empíricas. Para enriquecer o debate derivado da experiência do auxílio emergencial, a identificação e a justificação normativa do problema social que queremos enfrentar com esse programa são demandas urgentes.

\section{CONSIDERAÇÕES FINAIS}

A situação trágica da pandemia da covid-ıg não só acarretou um elevadíssimo número de mortes, como também graves impactos econômicos, afetando a vida de importante proporção da população brasileira. E é provável que as consequências perniciosas se estendam por muito tempo; o que nos leva à necessidade de repensar nosso sistema de proteção social. Buscamos realizar algumas considerações normativas sobre o futuro dos programas de transferência de renda, à luz da experiência do auxílio emergencial e dialogando com a literatura contemporânea sobre renda básica universal. O auxílio serviu de mote, no debate público e acadêmico, para pensar acerca das insuficiências das estratégias de proteção. Debruçamo-nos sobre alguns dos pontos encontradiços nos argumentos públicos para refletir sobre saídas e alternativas propostas. Nosso propósito não foi o de elaborar um desenho específico de programa ou avaliar políticas; mas sim o de evidenciar a natureza dos dilemas morais e objetivos distributivos subjacentes aos debates atuais.

Norteamo-nos por três princípios de justiça - o igualitarismo, o prioritarismo e o suficientarismo - e argumentamos acerca da importância de aproximar as literaturas teórico-normativas e empíricas sobre desigualdades. Assim como a grade analítica normativa ilumina questões que, de outro modo, seriam tipicamente negligenciadas por analistas e formuladores de políticas públicas; a consideração sistemática de evidências pode desencadear inovações na consideração dos princípios de justiça. Ilustramos este último caso por meio da consideração diacrônica da distribuição de renda (fundados em estudos sobre a volatilidade de renda), o que engendrou alterações substantivas nos modos como concebemos a prioridade, a suficiência e a igualdade.

Recebido em 09/I I/2020 | Revisto em I7/06/202 I | Aprovado em 25/06/202I 
Marcos Paulo Lucca-Silveira é professor da Escola de Economia de São Paulo da Fundação Getulio Vargas e pesquisador da Fundação José Luiz Egydio Setúbal. Doutor em ciência política pela Universidade de São Paulo e pesquisador associado ao Centro de Estudo da Metrópole (CEM-USP), no qual fez pós-doutorado, atua em teoria política normativa, ética aplicada e políticas públicas. É coautor do artigo "Investigating the mobility capabilities and functionings in accessing schools through walking: a quantitative assessment of public and private schools in São Paulo" (Brazil).

Rogério Jerônimo Barbosa é professor do Instituto de Estudos Sociais e Políticos da Uerj. Doutor em sociologia pela USP, é pesquisador associado ao Centro de Estudos da Metrópole e do Princeton Brazil Lab. Pesquisa e publica sobre os temas de desigualdade de renda, mercado de trabalho e educação. É coautor de "Educational expansion, inequality and poverty reduction in Brazil: a simulation study" e de "Distribuição de renda nos anos 20ıo: uma década perdida para desigualdade e pobreza". 


\section{NOTAS}

I Milton Friedman (1968) apresenta uma proposta de negative income tax, a qual possui alguma similaridade com a proposta de renda básica universal, segundo parte da literatura contemporânea. O artigo de Bidadanure (20I9) apresenta uma excelente revisão sobre o debate de renda básica, a qual seguimos em parte desta seção.

2 Já no Brasil, destacam-se os trabalhos acadêmicos e proposições política de Eduardo Suplicy (2013).

3 Para mais detalhes sobre as regras, ver Souza et al. (2020).

4 Considerando uma linha de pobreza de um terço do salário-mínimo vigente em 2020. A taxa de pobreza para 2019 foi calculada a partir da Pnad Contínua Anual de 2019, com valores deflacionados para maio de 2020. A taxa de pobreza para a quarta semana de maio foi calculada com a Pnad-Covid.

5 A linha de pobreza adotada pelo Banco Mundial para países de renda média-alta, como o Brasil, é de US\$ 5,50 PPP 20I I por dia per capita. Convertidos em R $\$$ e mensalizado, esse valor corresponderia a $\mathrm{R} \$ 434$ per capita em 20I9. A média das linhas de pobreza calculadas por Sônia Rocha (20I5) para o ano de 2014 era de $\mathrm{R} \$ 249$,I3 per capita mensais. Em valores de julho de 2019, isso seria equivalente a $R \$ 326,4$ I.

6 Um programa nesse formato é conhecido na literatura como capital básico. Essa proposta pode ser encontrada na formulação de Ackerman e Alstott (2000, 2006).

7 A literatura original sobre a questão não delimita em qual quantil da distribuição o limiar de suficiência deveria ser fixado. Frankfurt (20I5) sugere que esse patamar seria bem mais exigente que as usuais linhas de pobreza.

8 Ver Bidadanure (20I9) para referências sobre essas razões.

9 O exemplo dos surfistas, que motivou a imagem de capa do livro clássico de Van Parijs (I995), é sempre apresentado na literatura sobre renda básica como uma crítica a posições igualitárias apresentadas por outros importantes filósofos, como John Rawls (200I: I79), que defende que instituições justas não devem subsidiar aqueles que optam por surfar todos os dias e não usam suas capacidades produtivas. 
Io O parentesco com funcionalistas como Davis e Moore (I945) não é fortuito.

I I A renda básica universal, assim como o Programa Bolsa Família, já foi objeto de considerações teóricas centradas em dimensões normativas. Entre outros trabalhos, as contribuições realizadas por Josué Pereira da Silva, com ênfase em questões de reconhecimento, merecem destaque. Considerações normativas centradas na questão das condicionalidades ou contrapartidas de programas focalizados, como presentes no PBF, foram objeto de reflexão normativa pelo sociólogo (Silva, 2009), que também apresenta uma análise dos discursos recentes sobre renda básica universal no Brasil e mundo contemporâneo (Silva, 20I9). Já um debate centrado nos efeitos positivos na autonomia das beneficiárias do PBF está presente em Leão Rego e Pinzani (2013). Agradecemos aos pareceristas as sugestões bibliográficas, incorporadas nesta nota.

I 2 Ver discussão apresentada na nota 5.

I3 Afinal, a aprovação de emendas constitucionais exige supermaiorias, dois turnos de votação em cada uma das casas legislativas.

\section{REFERÊNCIAS}

Ackerman, Bruce \& Alstott, Anne. (2006). Why stakeholding? In: Ackerman, Bruce; Alstott, Anne \& Van Parijs, Philippe. Redesigning distribution: basic income and stakeholder grants as cornerstones for an egalitarian capitalism. London/New York: Verso, p. 43-65.

Ackerman, Bruce \& Alstott, Anne. (2000). The stakeholder society. New Haven: Yale University Press.

Barbosa, Rogério J.; Souza, Pedro H. G. Ferreira de \& Soares, Sergei S. D. (2020). Distribuição de renda nos anos 20ıо: uma década perdida para desigualdade e pobreza. Brasília: Ipea (Texto para Discussão, v. 2610).

Barbosa, Rogério J.; Prates, Ian \& Meirelles, Thiago de Oliveira. (2020). A vulnerabilidade dos trabalhadores brasileiros na pandemia da Covid-I9. Boletim - Rede de Pesquisa Solidária Políticas Públicas \& Sociedade, 2. 
Barbosa, Rogério J. et al. (2020a). Auxílio de R \$600,00 precisa continuar e pode ser financiado por contribuição emergencial sobre altas rendas. Boletim - Rede de Pesquisa Solidária Políticas Públicas \& Sociedade, 8.

Barbosa, Rogério J. et al. (2020b). Crise altera o perfil do trabalho em casa e do teletrabalho. Desigualdade digital reduz rendimentos e rebaixa atividade econômica. Boletim - Rede de Pesquisa Solidária Políticas Públicas \& Sociedade, I6. Bidadanure, Juliana U. (2019). The political theory of universal basic income. Annual Review of Political Sciences, 22, p. $48 \mathrm{I}-50 \mathrm{I}$.

Casal, Paula. (2007). Why sufficiency is not enough? Ethics, II $7 / 2$.

Davis, Kingsley \& Moore, Wilbert. (1945). Some principles of stratification. American Sociological Review, 10/2.

Frankfurt, Harry. (2015). On inequality. New Jersey: Princeton University Press.

Friedman, Milton. (1968). The case for a negative income tax: a view from the right. In: Bunzel, John. (ed.). Issues in American public policy. Englewood Cliffs: Prentice-Hall, p. III-I2O.

Gentilini, Ugo, et al. (eds). (2019). Exploring universal basic income: a guide to navigating concepts, evidence, and practices. Washington, DC: World Bank Publications.

Hecksher, Marcos \& Barbosa, Rogério. (202I). Renda e trabalho durante a pandemia. Boletim do Observatório Fiocruz Covid-I9, semanas epidemiológicas I4 e I5. Disponível em: https://portal.fiocruz.br/sites/portal.fiocruz.br/files/documentos/boletim_covid_2O2I-semanas_I4-I5-red.pdf. Acesso em io jun. 202I.

King Jr., Martin Luther. (2010). Where do we go from here: chaos or community? Boston: Beacon.

Leão Rego, Walquíria \& Pinzani, Alessandro. (2013). Vozes do Bolsa Família: autonomia, dinheiro e cidadania. São Paulo: Editora Unesp.

Levy, Horacio; Matsaganis, Manos \& Sutherland, Holly. (2013). Towards a European union child basic income? Within and between country effects. International Journal of Microsimulation, I/6, p. 63-85. 
Li, Sabrina L. et al. (202I). Higher risk of death from Covid-ı in low-income and non-white populations of São Paulo, Brazil, BMJ Global Health, 6/4.

Lucca-Silveira, Marcos Paulo. (2017). Justiça distributiva e saúde: uma abordagem igualitária. Tese de Doutorado. PPGCP/Universidade de São Paulo.

Mostafa, Joana \& Santos, Thuany dos. (20I6). Limitações de um teste de meios via predição de renda: evidências de uma aplicação no programa bolsa família. Brasília/Rio de Janeiro: Ipea (Texto para discussão).

Nassif-Pires, Luiza; Cardoso, Luisa \& Oliveira, Ana Luíza Matos de. (202I). Gênero e raça em evidência durante a pandemia no Brasil: o impacto do auxílio emergencial na pobreza e extrema pobreza. Nota de Política Econômica, Io. Paine, Thomas. (1797). Agrarian justice. London: R. Folwell. Paiva, Luis Henrique et al. (202I). A reformulação das transferências de renda no Brasil: simulações e desafios. Brasília: Ipea (Texto para discussão, I).

Parfit, D. (2002). Equality or priority. In: Clayton, Matthew \& Williams, Andrew (eds.). The ideal of equality. Edition printed with correction. New York: Palgrave Macmillan.

Rawls, John. (200I). Justice as fairness: a restatement. Cambridge, MA: Harvard University Press.

Rocha, Sonia. (20I5). Indicadores de pobreza, segundo unidades de federação, regiões e estratos de residência - 2014. Planilha do Excel. Rio de Janeiro: Iets.

Roemer, John E. (2004). Eclectic distributional ethics. Politics, Philosophy \& Economics, 3/3, p. 267-28I. Disponível em: https://doi.org/Io.II77/I470594X04046238. Acesso em 05 mar. $202 \mathrm{I}$.

Sen, Amartya \& Foster, James. (I997). On economic inequality. Oxford University Press.

Silva, Josué Pereira da. (2019). Renda básica em tempos difíceis. São Leopoldo: Universidade do Vale do Rio dos Sinos (Cadernos IHUideias).

Silva, Josué Pereira da. (2009). Reconhecimento, redistribuição e as ambivalências do discurso sobre o Bolsa Família. Ciências Sociais Unisinos, 45/3, p. 196-205. 
Soares, Sergei. (20I0). A volatilidade de renda e a cobertura do Programa Bolsa Família. Brasil em desenvolvimento, 3. Soares, Sergei Suarez Dillon et al. (2019). A universal child grant in Brazil: what must we do, and what can we expect from it?. Brasília: International Policy Centre for Inclusive Growth (Working Paper I8I).

Souza, Pedro H.G. Ferreira de et al. (2020). Estimativas de público elegível e custos do benefício emergencial criado pelo PL 9.236/2017. Brasília: Ipea (Nota Técnica da Disoc, 60). Suplicy, Eduardo. (2013). Renda da cidadania: a saída é pela porta. 7 ed. São Paulo: Editora Cortez.

Van Parijs, Philippe \& Vanderborght, Yannic. (2017). Basic income: a radical proposal for a free society and a sane economy. Cambridge, MA: Harvard Univ. Press, 2017.

Van Parijs, Philippe. (I995). Real Freedom for All. Oxford, UK: Clarendon.

Van Parijs, Philippe. (1994). Capitalismo de renda básica. Lua Nova, 32, p. 69-9I. 


\section{O FUTURO DAS TRANSFERÊNCIAS DE RENDA NO BRASIL: DILEMAS EMPÍRICOS E NORMATIVOS PARA UM PROGRAMA PÓS-PANDEMIA E PÓS-AUXÍLIO EMERGENCIAL}

Resumo

O objetivo desse artigo é refletir sobre os dilemas normativos que rondam o futuro das transferências de renda no Brasil, pós-pandemia. Iniciamos pela análise dos impactos da pandemia sobre resultados socioeconômicos e dos efeitos do auxílio emergencial sobre a distribuição de renda. Abordamos a discussão atual sobre os limites do Bolsa Família e o conceito de renda básica universal. Introduzimos três princípios de justiça para nortear nossa análise normativa: o igualitarismo, o prioritarismo e o suficientismo. Mostramos como esses conceitos permitem fazer questões sobres os objetivos de políticas e sobre dilemas morais implicados nos desenhos e métodos de implementação. Mostramos ainda que os próprios princípios de justiça são modificados quando levamos em conta aspectos práticos e não ideais da realidade sobre quais políticas são elaboradas.

THE FUTURE OF CASH TRANSFERS IN BRAZIL: EMPIRICAL AND NORMATIVE DILEMMAS FOR A POSTPANDEMIC AND POST-EMERGENCY AID PROGRAM

Abstract

In this article, we analyze the normative dilemmas that surround the future of cash transfers in Brazil, after the Covid-I9 pandemic. We begin by analyzing the impacts of the pandemic on socioeconomic outcomes and the effects of emergency aid on the income distribution. We address the current discussion about the limits of Bolsa Família and how the concept of a universal basic income. We introduce three principles of justice to guide our normative analysis: egalitarianism, prioritarianism, and sufficientarianism. We show how these concepts allow us to ask unique questions about policy objectives and moral dilemmas implied by the policy designs and methods of implementation. We also show that the principles of justice themselves are modified when we take into account practical and non-ideal aspects of the reality on which policies are elaborated.
Palavras-chave

Auxílio emergencial; renda básica universal; igualitarismo; prioritarismo; suficientarismo.

Keywords

Emergency aid; universal basic income; egalitarianism; prioritarianism; sufficientarianism. 